\begin{tabular}{c|c|c}
\hline \hline & CLIMATE RESEARCH & Published August 4 \\
Vol. 27: 59-75, 2004 & Clim Res & \\
\hline
\end{tabular}

\title{
Simulated sea level in past and future climates of the Baltic Sea
}

\author{
H. E. Markus Meier*, Barry Broman, Erik Kjellström \\ Swedish Meteorological and Hydrological Institute, Rossby Centre, 60176 Norrköping, Sweden
}

\begin{abstract}
Sea levels of the Baltic Sea in past and future climates were investigated based upon 6hourly regional model results. For the future climate, the Rossby Centre Atmosphere Ocean model was used to perform a set of $30 \mathrm{yr}$ time slice experiments. For each of the 2 driving global models HadAM3H and ECHAM4/OPYC3, one control run (1961 to 1990) and 2 scenario runs (2071 to 2100) based upon the scenarios A2 and B2 of the Special Report on Emission Scenarios (SRES) were conducted. To estimate uncertainties in the global and regional models, 3 sea level scenarios for the Baltic Sea were compiled assuming global average sea level rises between 0.09 and $0.88 \mathrm{~m}$ and considering land uplift and the impact of regional changes in wind direction and velocity from the time slice experiments. In the scenarios forced with ECHAM4/OPYC3 the mean sea level between October and April increases significantly compared to the control climate, and storm surges increase even more than monthly mean sea level. In the scenarios forced with HadAM3H the changes are mostly not significant. Depending on the sea level rise, the risk of flooding at the coasts may either decrease in the entire Baltic, or it may increase, especially at the eastern ends of the Gulf of Finland and Gulf of Riga and in Gdansk Bay. Here, maximum changes of about $1 \mathrm{~m}$ are found in the winter mean $99 \%$ quantiles of the sea level. For the past climate the regional ocean model was forced with reconstructed surface wind fields for 1903 to 1998 . The results are close to observations, but storm surges in the western Baltic are underestimated.
\end{abstract}

KEY WORDS: Baltic Sea $\cdot$ Sea level $\cdot$ Ocean modeling $\cdot$ Regional climate scenarios $\cdot$ Spatial planning

Resale or republication not permitted without written consent of the publisher

\section{INTRODUCTION}

The Baltic is a semi-enclosed sea with a surface area of $421 \times 10^{9} \mathrm{~m}^{2}$ and a volume of $22 \times 10^{12} \mathrm{~m}^{3}$, including the Kattegat (Fig. 1). Due to the freshwater excess, mainly from river discharge, the salinity decreases from almost oceanic in the northern Kattegat to almost freshwater in the northern Bay of Bothnia and eastern Gulf of Finland. Partly due to the salinity gradient and partly due to a mean west wind component (about 1 to $2 \mathrm{~m} \mathrm{~s}^{-1}$, averaged over the Baltic area; Meier \& Kauker 2003a), observed mean sea surface height (SSH) increases from the Kattegat to the Gulf of Finland and Bay of Bothnia by about 25 and $32 \mathrm{~cm}$, respectively (Fig. 1).

There is a pronounced annual cycle of the sea level, with maximum variance in late autumn to early winter (Samuelsson \& Stigebrandt 1996). This variance increases from south to north for periods longer than
1 mo, similar to the oscillations in a fjord, with a node in the mouth and increasing amplitudes toward the inner part of the basin. For periods $<1$ mo, variance maxima are located in the Belt Sea and Arkona Sea and in the Bay of Bothnia and Gulf of Finland. In this case the Baltic oscillates like a closed basin with maximum amplitudes at the extreme ends and a node in between (Samuelsson \& Stigebrandt 1996). Using 2dimensional numerical models, Wübber \& Krauss (1979) computed eigen-modes (seiches) with periods of $31 \mathrm{~h}$ between the western Baltic and the Bay of Bothnia, and $26 \mathrm{~h}$ between the western Baltic and the Gulf of Finland. However, seiches are energetically unimportant (Magaard \& Krauss 1966), very likely due to strong bottom friction associated with the complex topography.

During the 20th century the annual maximum sea levels and the annual variability show statistically sig- 

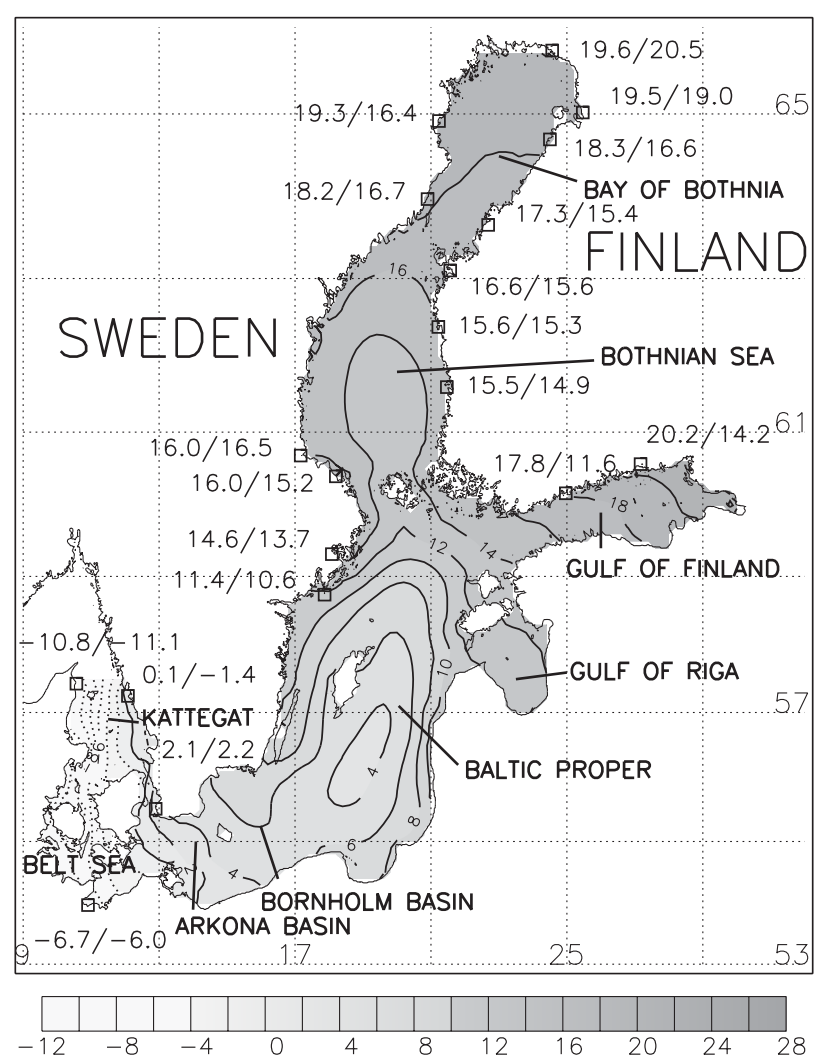

Fig. 1. Mean sea surface height ( $\mathrm{SSH}, \mathrm{cm}$ ) of hindcast simulation H1 for 1903 to 1998 in the Nordic height system 1960 (NH60). Numbers at tide gauge locations indicate model results (left) and geodetic solutions with geostrophic closure of Ekman \& Mäkinen (1996) (right). Contour interval: $2 \mathrm{~cm}$

nificant positive trends, with the most pronounced increase during the 1960s and 1970s (Johansson et al. 2001). The sea level variability of periods $<2 \mathrm{wk}$ is controlled by meteorological forcing and shows large decadal variability. A common feature for all basins of the Baltic Sea is a minimum in variability during the 1960s and a subsequent increase in winter time variability up to the 1980s. However, the overall trend in the SD of $10 \mathrm{~d}$ periods during the 20th century is statistically not significant (Johansson et al. 2001). Similar results were reported for long-term variability and trends of synoptic-scale storm activity derived from air pressure data (Alexandersson et al. 1998, 2000).

The main factors affecting the long-term mean sea level (MSL) in the Baltic Sea are (1) uplift of the land, (2) eustatic sea level rise, and (3) water balance of the Baltic Sea (Johansson et al. 2003). The land uplift (or the glacio-hydro-isostatic effect) is the Earth's response to past changes in ice and water loads. Relative to the MSL a long-term maximum uplift of $9.0 \mathrm{~mm} \mathrm{yr}^{-1}$ is found in the Bay of Bothnia (Ekman 1996).

MSL is not stationary in time, but rises relative to the geoid. This eustatic sea level rise is estimated at
1 to $2 \mathrm{~mm} \mathrm{yr}^{-1}$ during the 20th century (Gornitz 1995). In global atmosphere-ocean general circulation models (AOGCMs), at least one-third of the anthropogenic eustatic sea level rise in the 20th century is caused by thermal expansion, which has a geographically nonuniform signal in sea level change (Church et al. 2001). Other factors are the recent melting of glaciers and ice caps in Greenland and Antarctica and the long-term development of ice sheets. The largest uncertainty of the model results is in the terrestrial storage terms (Church et al. 2001). The global average sea level is projected to rise from 1990 to 2100 in the range 0.09 to $0.88 \mathrm{~m}$ (Church et al. 2001). This assumes that the West Antarctic ice sheet, which contains enough ice to raise the global average sea level by $6 \mathrm{~m}$, is stable.

The third factor affecting MSL is the water balance of the Baltic Sea, which is closely related to the sea level pressure (SLP) patterns over the North Atlantic (Heyen et al. 1996). The dominant pattern over Northern Europe in winter is described by the North Atlantic Oscillation (NAO) index (e.g. Hurrell 1995, P.D. Jones et al. 1997). The sea level variability on time scales longer than $1 \mathrm{yr}$ correlates significantly with the NAO index (e.g. Johansson et al. 2001, Andersson 2002, Meier \& Kauker 2002). Although NAO is the dominant large-scale SLP pattern over the Baltic Sea, the variability of NAO explains only $32 \%$ of the total variability on average (Kauker \& Meier 2003). The remaining variability is explained by 2 other teleconnection patterns, the Scandinavia pattern and the East Atlantic/West Russia pattern (Barnston \& Livezey 1987). These 3 SLP patterns explain sea level variability at the location Landsort (see Fig. 8) almost completely (Kauker \& Meier 2003). An increase of the NAO index has been found in greenhouse gas scenarios of some global models (Ulbrich \& Christoph 1999), resulting in increased winter mean wind speeds. This might lead to an increase of the winter mean sea level in the Baltic Sea. However, the correlation between sea level and NAO index could differ in the future climate, because other factors arising from increased greenhouse gas concentration might affect global as well as local atmospheric circulation patterns.

Regional sea level scenarios have been calculated before. Using a statistical downscaling method, Baerens \& Hupfer (1999) found that storm surges on the German Baltic coast will not change significantly. Similar results have been reported for the North Sea (Langenberg et al. 1999, Kauker \& Langenberg 2000). The winter means of high water levels along the North Sea coast will increase slightly, but the high intramonthly percentiles - reduced by the winter means will not change significantly. However, an increase in extreme surge heights relative to MSL has been pre- 
dicted by Lowe et al. (2001) for many locations around the United Kingdom. They analyzed simulated surge heights with a $5 \mathrm{yr}$ or $50 \mathrm{yr}$ return period from a dynamical downscaling experiment and found that the assumed change in MSL of $0.5 \mathrm{~m}$ is the dominant effect, but in some areas (e.g. the English Channel) the effect of the altered meteorological forcing on storm surges is of comparable importance. Johansson et al. (2004) calculated MSL scenarios for the Finnish coast in the 21st century. They considered land uplift, the projected global average sea level rise and the projected trends of the leading SLP component in AOGCM scenarios; SLP was used to estimate changes in the water balance associated with changes of the NAO. Johansson et al. (2004) concluded that the past trend in MSL in the Gulf of Finland will not continue in the future, because an accelerated global average sea level rise will offset the land uplift.

In this study, we used a regional ocean climate model to analyze sea levels in past and future climates of the Baltic Sea, as the skill of state-of-the-art ocean models in reproducing observed sea levels is sufficiently high (e.g. Meier 1996, Meier \& Kauker 2003a, Meier et al. 2003). Based upon the same dynamical downscaling approach as applied here, regional scenarios for other variables like sea ice, sea surface temperature (SST), surface heat fluxes or steady state salinity have been studied (e.g. Haapala et al. 2001, Meier 2002a,b, Meier \& Kauker 2003b, Döscher \& Meier 2004, Meier et al. 2004).

\section{METHODS}

\subsection{Dynamical downscaling}

The Rossby Centre Ocean model (RCO), a regional coupled ice-ocean model (Meier et al. 1999, 2003, Meier 2001, Meier \& Faxén 2002), was applied to calculate sea level scenarios for the Baltic Sea. The model domain covers the Baltic Sea with open boundary conditions in the northern Kattegat. It uses 6-hourly atmospheric surface fields and monthly river discharges from the fully coupled atmosphere-ice-ocean model RCAO as forcing (see Döscher \& Meier 2004, Meier et al. 2004, Räisänen et al. 2004). Due to the coupling frequency of the atmospheric surface fields, extreme storm surges might be underestimated. Instead of analyzing the sea level results of RCAO we performed RCO off-line experiments, because river discharges in the RCAO control simulations are overestimated and affect salinity in the Baltic Sea significantly (Meier \& Kauker 2003b) (another reason is that the sea levels in these experiments are biased due to a technical error in the coupling between atmosphere and ocean models affecting SLP at gridpoints near the coast; other variables are not affected). In the RCO offline control experiments the freshwater supply has been corrected so that the total mean freshwater inflow equals the observed inflow for 1961 to 1990 (Meier \& Kauker 2003b). Correspondingly, in the offline scenario experiments the total mean freshwater inflow is the sum of the observed inflow for 1961 to 1990 plus the calculated changes between scenario and control experiments in RCAO. The sea level at the open boundary of RCO in the northern Kattegat is calculated every $6 \mathrm{~h}$ from the meridional SLP difference across the North Sea after Gustafsson \& Andersson (2001). In case of water inflow into the Baltic, temperature and salinity values at the boundaries are nudged towards observed climatological profiles. In case of water outflow from the Baltic, a radiation condition is utilized (Stevens 1990). Such a simplified treatment of the open boundary in the Kattegat is sufficient as long as the salinity of about $33 \%$ does not change in the deep water of the Kattegat (Meier \& Kauker 2003b). The horizontal grid distance amounts to 6 nautical miles, and 41 vertical levels with layer thicknesses between 3 and $12 \mathrm{~m}$ were utilized. In all experiments the simulated sea levels were analyzed from 6-hourly snapshots. The Nordic height system 1960 (NH60) was used as reference (Ekman \& Mäkinen 1996).

RCAO is a regional climate model for Northern Europe, including parts of the North Atlantic and the Baltic Sea (Döscher et al. 2002). The regional scenarios differ depending on the applied GCM at the lateral boundaries, and depending on the emission scenarios for greenhouse gases, aerosols and aerosol precursors. A series of 6 time slice experiments of $30 \mathrm{yr}$ duration was performed, using 2 GCMs: (1) $\operatorname{HadAM} 3 \mathrm{H}$, an atmospheric version of HadCM3 (Gordon et al. 2000; R. Jones, D. Hassel, J. Murphy unpubl.) from the Hadley Centre (UK); (2) ECHAM4/OPYC3 (Roeckner et al. 1999) from the Max Planck Institute for Meteorology (Germany). Hereinafter, the associated regional RCO simulations are denoted with HC and MPI, respectively. The control simulations (CTL) represent the recent (1961 to 1990) climate and the scenario simulations (A2, B2) represent the climate of the late 21st century (2071 to 2100). Following the IPCC Special Report on Emission Scenarios (SRES; Nakićenović et al. 2000), the A2 scenario assumes a more rapid increase in emissions of the major anthropogenic greenhouse gases compared to the B2 scenario. The 4 scenarios, 2 driving global models forced with 2 emission scenarios (A2, B2), characterize the uncertainty of future projected sea level changes. All control and scenario time slices were initialized with temperature and salinity profiles observed from 1959 to 1962 . Initial sea level and velocities were set to zero. The spin-up strat- 
Table 1. Acronyms for models and model runs

\begin{tabular}{|c|c|c|}
\hline Acronym & Model & Source \\
\hline ECHAM4/OPYC3 & AOGCM of the Max Planck Institute for Meteorology (Germany) & Roeckner et al. (1999) \\
\hline HadCM3 & AOGCM of the Hadley Centre (UK) & Gordon et al. (2000) \\
\hline HadAM3H & AGCM of the Hadley Centre (UK), SST and sea ice from HadCM3 & R. Jones et al. (1997) \\
\hline $\mathrm{RCO}$ & Rossby Centre Ocean model & Meier et al. (2003) \\
\hline $\mathrm{RCAO}$ & Rossby Centre Atmosphere Ocean model & Döscher et al. (2002) \\
\hline RCAO-H & RCAO forced with boundary data from HadAM3H & Räisänen et al. (2004) \\
\hline RCAO-E & RCAO forced with boundary data from ECHAM4/OPYC3 & \\
\hline HCCTL & $\mathrm{RCO}$ control run forced with atmosphere data from RCAO-H & This study \\
\hline MPICTL & RCO control run forced with atmosphere data from RCAO-E & \\
\hline HCA2, HCB2 & RCO A2 and B2 scenario runs forced with atmosphere data from RCAO-H & \\
\hline MPIA2, MPIB2 & RCO A2 and B2 scenario runs forced with atmosphere data from RCAO-E & \\
\hline H1 & RCO hindcast run for 1903 to 1998 with reconstructed forcing & Meier \& Kauker (2003a) \\
\hline $\mathrm{H} 2$ & RCO sensitivity run with $34 \%$ increased freshwater inflow & Meier \& Kauker (2003b) \\
\hline H3 & RCO sensitivity run with $30 \%$ increased wind forcing & Meier \& Kauker (2002) \\
\hline
\end{tabular}

egy for the scenario time slices assumes that the stratification will not change significantly, i.e. freshwater supply and salt water inflow variability remain approximately at present-day values. This assumption is not valid for the scenarios driven by the ECHAM4/OPYC3, because runoff, net precipitation and wind speed change significantly (Meier \& Kauker 2003b, Räisänen et al. 2004). However, the error for the sea level may be small as shown in section 3.1. The spin-up problem has been discussed by Meier (2002b). Acronyms for models and model runs are given in Table 1.

\subsection{Hindcast and sensitivity experiments}

In addition to the control simulations we performed a hindcast simulation (H1) for 1903 to 1998 using reconstructed atmospheric surface fields (Kauker \& Meier 2003). H1 accurately reproduces temperature, salinity, sea level, sea ice, volume and salt fluxes on time scales of days to decades, mainly because the reconstructed atmospheric surface data and the other forcing fields have a good quality (Meier \& Kauker 2003a). Hence, simulated sea levels of H1 were used to correct sea level biases in the control simulations. In this so-called $\Delta$-change approach, the scenario sea level is calculated from the sum of the sea level in $\mathrm{H} 1$ and the difference between the sea level in the scenario run and the sea level in the central run. Further, sensitivity experiments for 1903 to 1998 were carried out to investigate the impact of $34 \%$ increased freshwater inflow (H2) and $30 \%$ increased wind speed (H3) on the mean SSH. These numbers were chosen because they characterize the range of the interannual variability in fresh- water inflow and wind forcing (cf. Schrum \& Backhaus 1999, Meier \& Kauker 2003b).

\subsection{Past eustatic sea level rise}

The eustatic sea level rise during the 20th century amounts to 1 to $2 \mathrm{~mm} \mathrm{yr}^{-1}$ (Church et al. 2001). This estimate was also the result of a review of studies based on a variety of methods, in which the MSL rise was $1.49 \pm 0.53 \mathrm{~mm} \mathrm{yr}^{-1}$ (Gornitz 1995, her Table 1). Ekman (1999a) found a value of $1.1 \mathrm{~mm} \mathrm{yr}^{-1}$ for the Stockholm sea level gauge. The Baltic sea level variability on time scales longer than 1 mo is to a large extent explained by sea level variations in the Kattegat (Samuelsson \& Stigebrandt 1996). However, long-term changes of the Kattegat/North Sea sea level could deviate from the global average sea level rise. The observations from 10 European tide gauges in Gornitz (1995) were taken in our study as representative of the Kattegat MSL. Hence, we assume in this study a MSL rise of $1.5 \mathrm{~mm} \mathrm{yr}^{-1}$ in the Baltic Sea for the 20th century.

\subsection{Sea level rise scenarios}

Based upon SRES scenarios the global average sea level rise has been calculated using AOGCMs (Church et al. 2001). For the complete range of 35 SRES scenarios including uncertainties in land ice changes, permafrost changes and sediment deposition, global average sea level is projected to rise from 1990 to 2100 by 0.09 to $0.88 \mathrm{~m}$ (Church et al. 2001, their Fig. 11.12). 
To estimate the impact of the uncertainties of the global and regional model results and of the emission scenarios of anthropogenic greenhouse gases, we calculated 3 sea level scenarios: (1) A 'higher case' scenario estimated using the regional model results with the largest monthly mean sea level increase, MPIA2 (see section 3.2), together with the upper limit for the global average sea level rise of $0.88 \mathrm{~m}$; however, one should keep in mind that the projected sea level rises in the global IPCC scenarios differ significantly at regional scales (Church et al. 2001, their Fig. 11.13), so that our 'higher case' scenario might be lower than the worst case simulated by the global models. (2) An 'ensemble average' calculated from the 4 regional scenarios (2 forcing models and 2 emission scenarios), assuming a global average sea level rise of $0.48 \mathrm{~m}$, which is the central value for all scenarios in Church et al. (2001). (3) A 'lower case' scenario estimated using the regional model with the smallest (i.e. zero) monthly mean sea level change, HCB2 (see section 3.2), together with the lower limit for the global average sea level rise of $0.09 \mathrm{~m}$. We do not imply that the 'ensemble average' scenario (Scenario 2) is the best estimate. The 3 scenarios were selected to illustrate the range of uncertainty.

\subsection{Land uplift}

Our scenario considered a linear land uplift for the $110 \mathrm{yr}$ between the 2 time slices (1961 to 1990, 2071 to 2100). We calculated the absolute land uplift rates from the station data of the apparent land uplift relative to the MSL for 1892 to 1991 in Ekman (1996), adding a eustatic sea level rise of $1.5 \mathrm{~mm} \mathrm{yr}^{-1}$ (section 2.3). Ekman's map of apparent land uplift is consistent with previous results for some Finnish tide gauges (Lisitzin 1964, Vermeer et al. 1988). The error is dominated by interannual variations in the volume of the Baltic Sea; this is estimated to be about $0.4 \mathrm{~mm} \mathrm{yr}^{-1}$ (Vermeer et al. 1988).

\section{RESULTS}

\subsection{Mean sea level (MSL)}

The simulated long-term mean SSH for 1903 to 1998 and the mean $\mathrm{SSH}$ in both control simulations are close to high-precision leveling data from Ekman \& Mäkinen (1996) (Fig. 1, Table 2). In the hindcast simulation we found a small overall positive bias during 1903 to 1998. The bias is largest for the Gulf of Finland. The reason might be an overestimation of the mean surface wind speed calculated from SLP, since hindcast simu-
Table 2. Model biases (cm) of the mean sea level in hindcast and control simulations

\begin{tabular}{|lccrr|}
\hline & \multicolumn{2}{c}{ Hindcast } & \multicolumn{2}{c|}{ Control } \\
& 1903-1998 & 1961-1990 & HCCTL & MPICTL \\
\hline Bay of Bothnia & 0.3 & 2.4 & -1.0 & 0.3 \\
Bothnian Sea & 0.4 & 2.8 & -4.4 & -0.9 \\
Gulf of Finland & 5.1 & 7.5 & -1.9 & 2.0 \\
Baltic proper & 0.8 & 3.0 & -3.2 & 0.4 \\
Western Baltic & -0.1 & 2.0 & 1.1 & 2.8 \\
Kattegat & -0.6 & 1.5 & 1.0 & 1.9 \\
Total & 0.8 & 3.1 & -1.9 & 0.7 \\
a Includes the Belt, Arkona and Bornholm Seas (see Fig. 1) \\
\hline
\end{tabular}

lations for 1980 to 1992 forced with surface wind fields associated with observed SLP showed similar results (Meier et al. 2003). In the control simulations the mean biases are either negative (HCCTL) or slightly positive (MPICTL) (Table 2). Thereby the mean $\mathrm{SSH}$ in MPICTL is generally higher compared to HCCTL with average and maximum differences of 3.1 and $4.6 \mathrm{~cm}$, respectively. The latter is found in the Gulf of Riga (not shown). In H1 the mean SSH for 1961 to 1990 is on average $2.3 \mathrm{~cm}$ higher compared to the mean $\mathrm{SSH}$ for

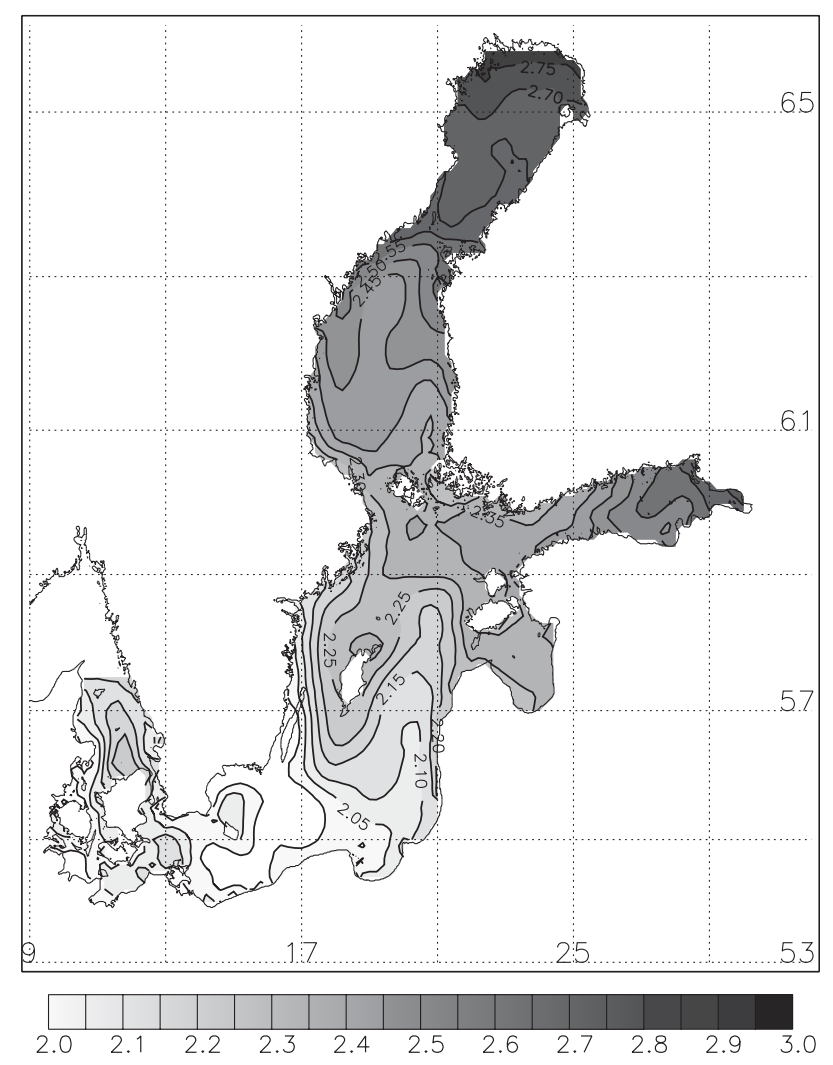

Fig. 2. Mean sea surface height (SSH, $\mathrm{cm}$ ) difference in $\mathrm{H} 1$ between 1961 to 1990 and 1903 to 1998. Contour interval: $0.05 \mathrm{~cm}$ 

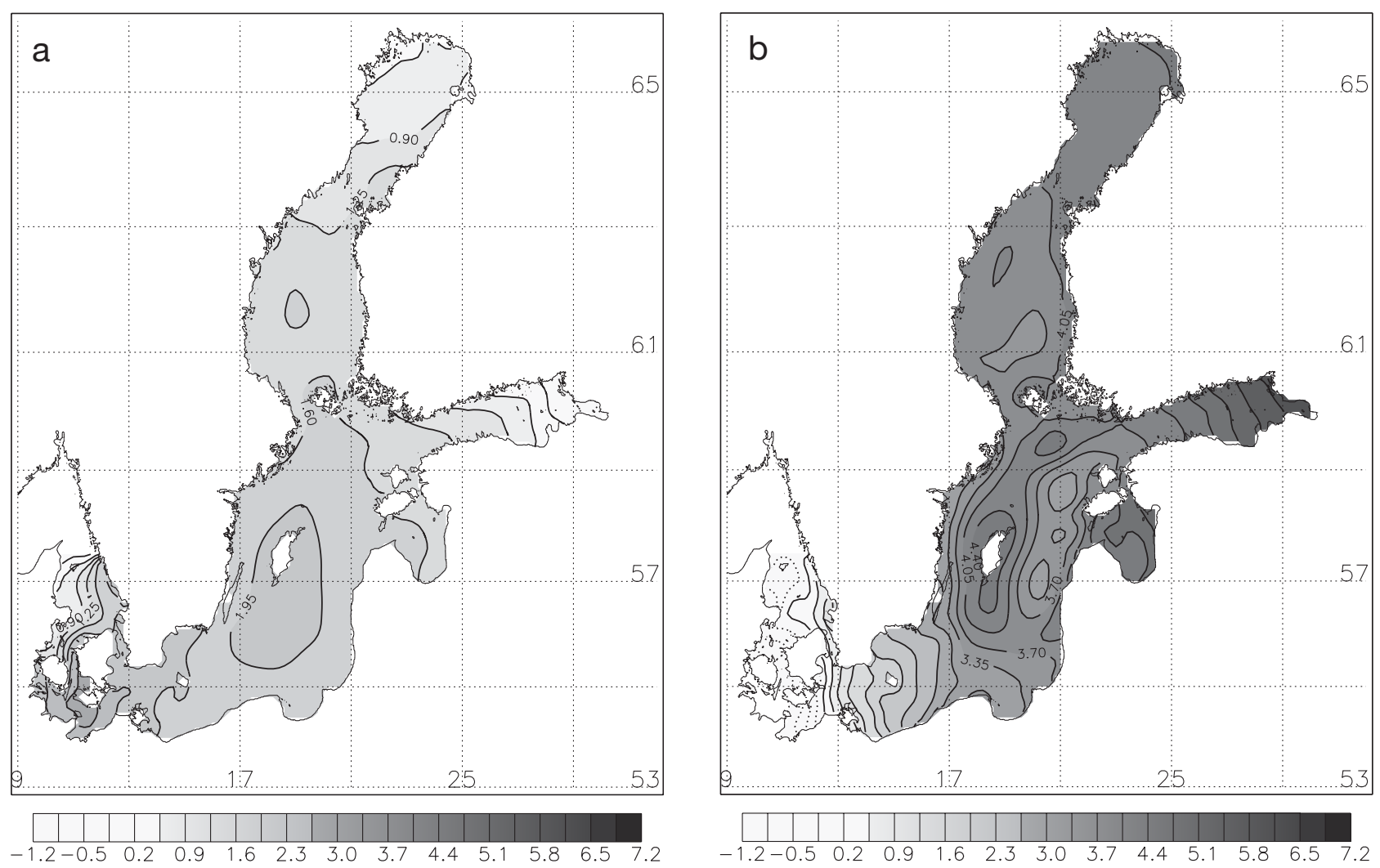

Fig. 3. Mean sea surface height ( $\mathrm{SSH}, \mathrm{cm})$ difference between sensitivity and hindcast experiments for 1961 to 1990 . (a) $34 \%$ increase in runoff $(\mathrm{H} 2-\mathrm{H} 1)$. (b) $30 \%$ increase in wind speed (H3-H1). Contour interval: $0.35 \mathrm{~cm}$
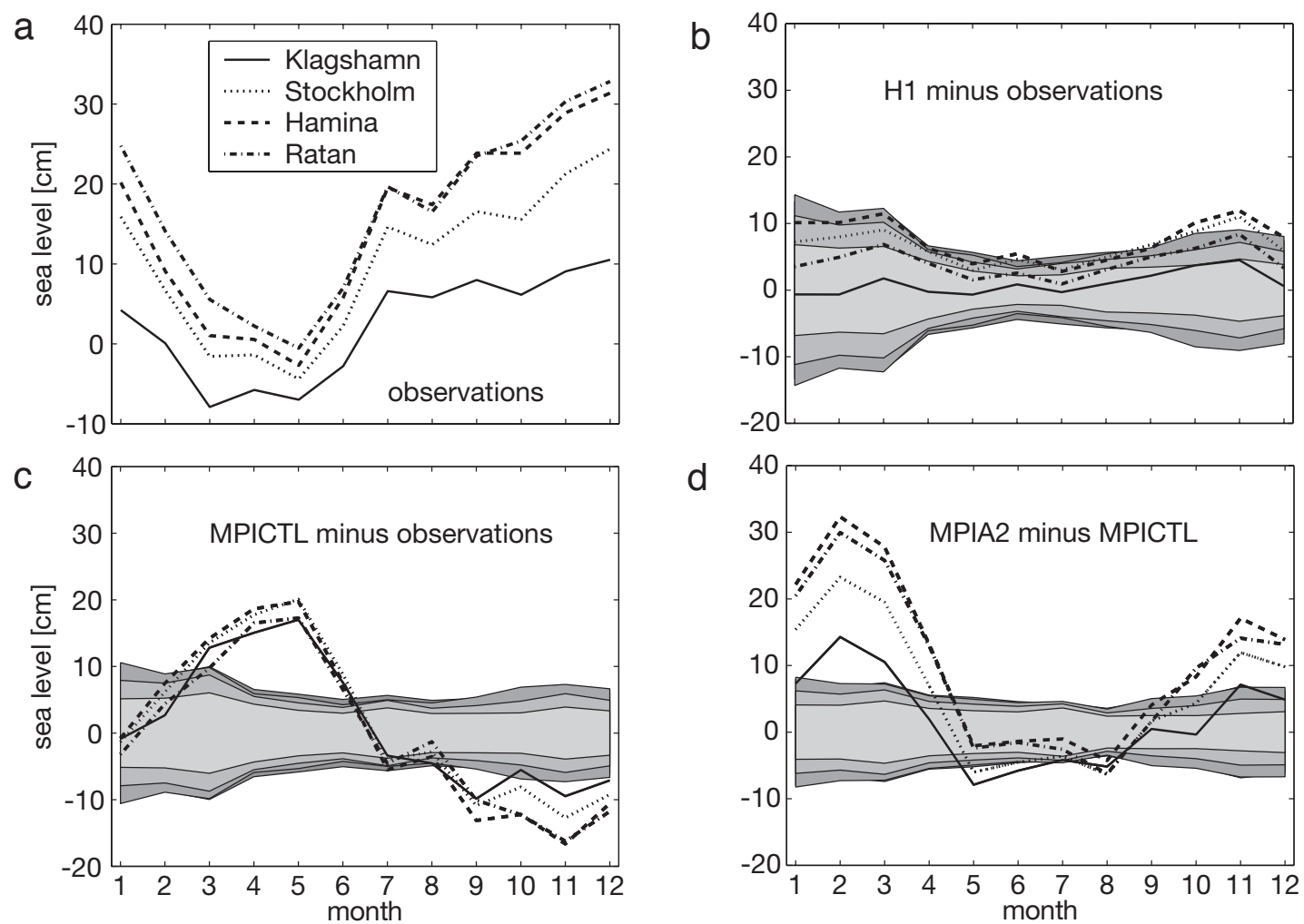

Fig. 4. Climatological monthly mean sea level (cm) for 1961 to 1990 at selected stations (see Fig. 7) in the Nordic height system 1960 (NH60). Shading indicates 99\% confidence limits of internal variability (from light grey for Klagshamn to dark grey for Ratan) 
1903 to 1998 (Fig. 2) due to the higher wind speeds during the 1980s when the NAO index was high.

To find out possible causes of the model biases sensitivity runs were performed. In Experiments $\mathrm{H} 2$ and $\mathrm{H} 3$ (Table 1) the impacts of freshwater inflow and wind speed on mean SSH were studied. We found that mean $\mathrm{SSH}$ is much more sensitive to wind than to freshwater inflow (Fig. 3).

Also the spatial patterns of the anomalies are quite different. In $\mathrm{H} 2$ the largest anomalies caused by additional freshwater inflow were in the Belt Sea and in the Gotland Basin south of Gotland. Whereas in H3 the largest anomalies caused by increased wind speed were in the Gulf of Finland. The sensitivity experiments suggest that the largest mean model biases are very likely caused by uncertainties in surface wind speed rather than by uncertainties in freshwater inflow. For a discussion of the biases of the SLP in the control simulations see Räisänen et al. (2003). However, sea level biases in the control simulations are relatively small and might be explained by internal variability, as the time slices of $30 \mathrm{yr}$ are rather short (Table 2).

\subsection{Mean seasonal cycle}

Sea level observations from several stations around the Baltic Sea show a pronounced annual cycle with high sea level in autumn and winter and low sea level in spring and early summer (Fig. 4a). The amplitudes of the annual cycle are largest at the northern end of the Bay of Bothnia and the eastern end of the Gulf of Finland, and smallest in the western Baltic. The interannual variability of the monthly mean sea level is much larger during autumn and winter than during summer (not shown). In the hindcast simulation (H1) the annual cycle is slightly overestimated in the northern and eastern parts of the Baltic (Fig. 4b). However, during most months these biases are statistically not significant. In this study the $99 \%$ confidence limits applying $t$-statistics are used to measure statistical significance. In both control simulations we found a less pronounced seasonal cycle causing statistically significant positive and negative biases during spring and autumn, respectively (for MPICTL see Fig. 4c). The sea level biases emanate from underestimated wind speeds (see 'Discussion').

In the MPIA2 scenario we found an increase in mean sea level between October and April compared to the control simulation (Fig. 4d). The winter mean sea level rise is most pronounced in the gulfs (Fig. 5). During May through August the mean sea level is slightly lower than in the control simulation. These changes follow approximately the wind speed changes averaged over the Baltic Sea surface (Räisänen et al. 2004, their Fig. 8i). We found in MPIA2 an increase of the

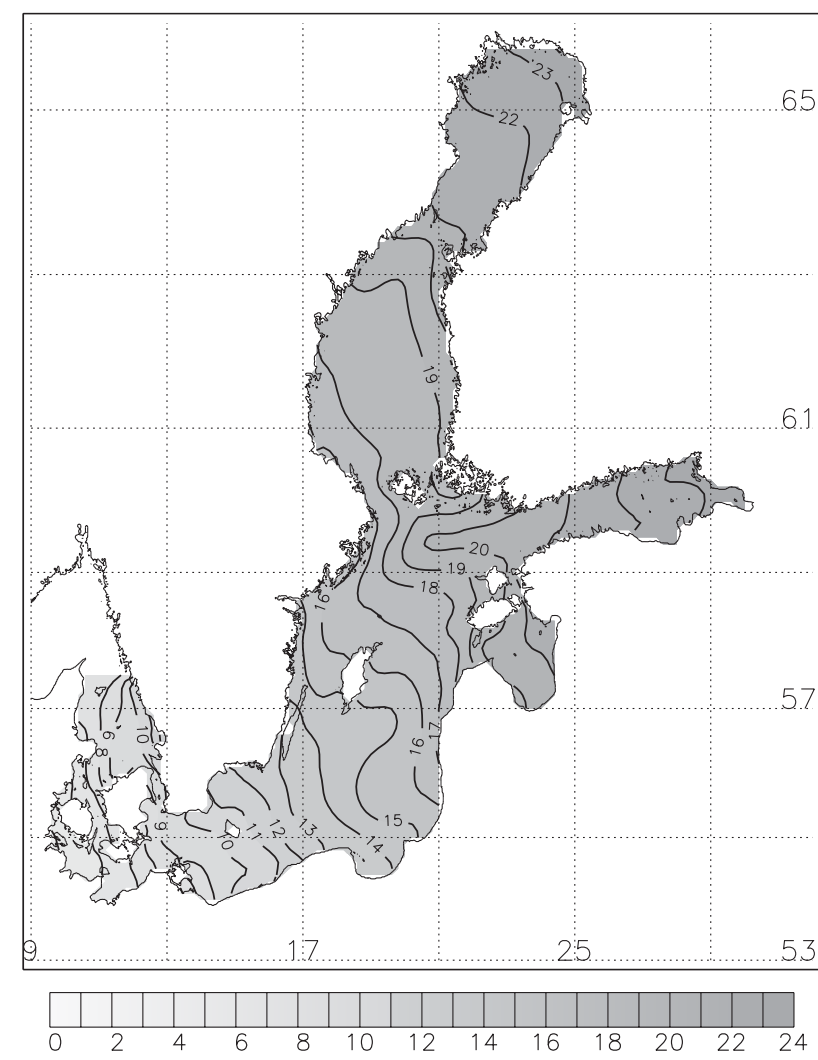

Fig. 5. Winter (December to February) mean sea surface height $(\mathrm{SSH}, \mathrm{cm})$ change in MPIA2. Contour interval: $1 \mathrm{~cm}$

winter mean wind speed of $3 \mathrm{~m} \mathrm{~s}^{-1}$ at the maximum. Wind speed changes are smaller in the Bay of Bothnia and Gulf of Finland than in other regions of the Baltic. They have westerly to southwesterly directions. The changes in MPIB2 are smaller, but show the same annual cycle compared to MPIA2 (Fig. 6).

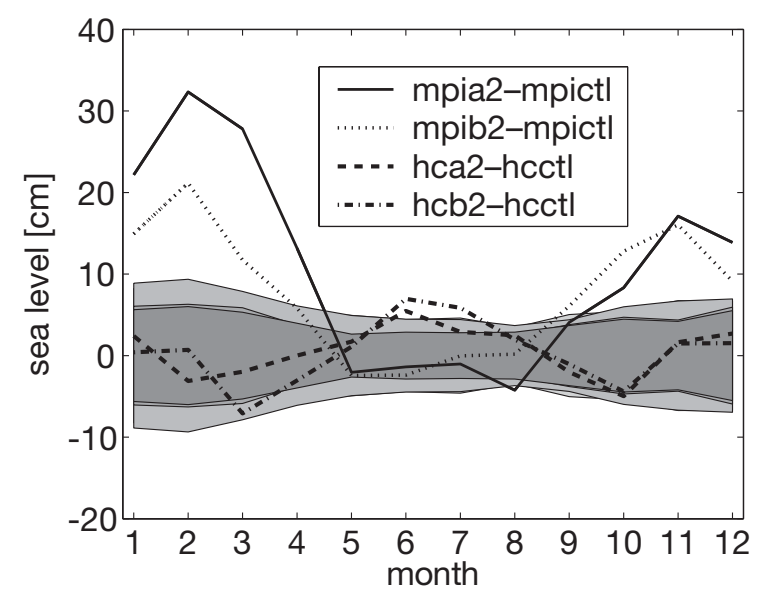

Fig. 6. Climatological monthly mean sea level (cm) changes at Hamina (see Fig. 7). Shading indicates 99\% confidence limits of internal variability (from light grey for MPIA2-MPICTL to dark grey for HCB2-HCCTL) 

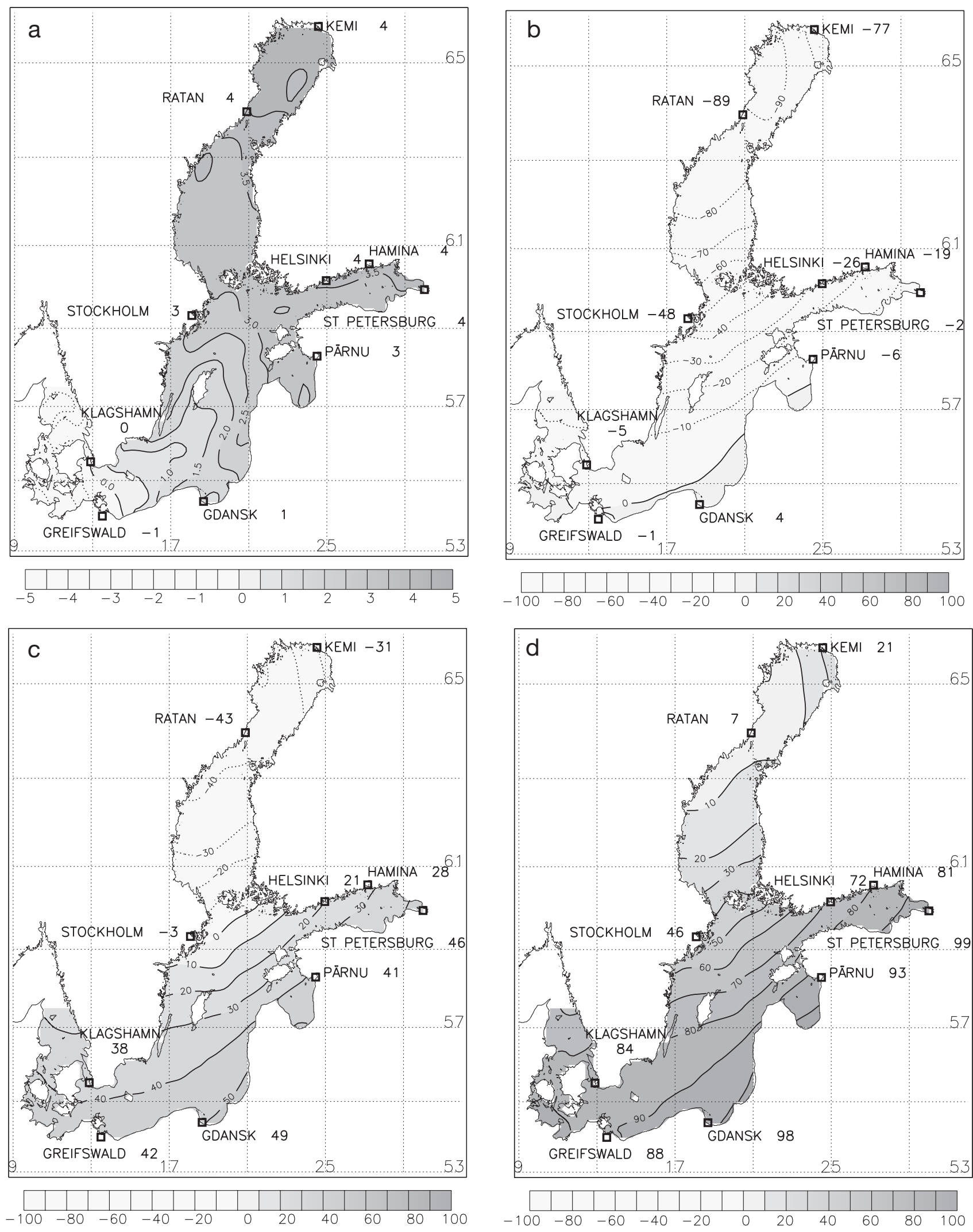

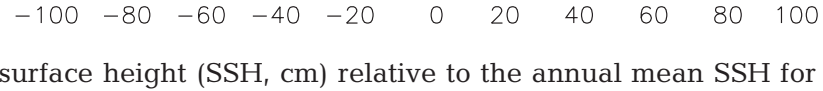

Fig. 7. Climatological winter (December to February) mean sea surface height ( $\mathrm{SSH}, \mathrm{cm}$ ) relative to the annual mean SSH for
1961 to 1990. (a) MPICTL. (b) 'Lower case' scenario (HCB2) with a sea level rise of $9 \mathrm{~cm}$. (c) 'Ensemble average' with a sea level rise of $48 \mathrm{~cm}$. (d) 'Higher case' scenario (MPIA2) with a sea level rise of $88 \mathrm{~cm}$. Land uplift is considered in the simulations. 
Regarding wind speed (Räisänen et al. 2004, their Fig. 8i), sea level changes are quite different between the HC and MPI scenarios. In HCB2 and HCA2 the small changes are statistically not significant during most months. The large differences between the MPI and $\mathrm{HC}$ scenarios during winter and spring can be attributed to the large differences in the driving models. In the ECHAM4/OPYC3 scenarios a stronger SLP gradient between northern and central Europe is simulated, compared to the HadAM3H scenarios, leading to stronger westerlies in northern Europe (Räisänen et al. 2004). Räisänen et al. (2004) suggest that changes in the ice cover and SST lead to decreased surface layer stability and thereby increased wind speed over the Baltic during winter. The sensitivity of wind speeds to SST and ice cover can be seen in the interannual variability in these parameters. Cold winters with extensive ice cover are generally less windy than mild winters with little ice. For instance, in the control runs for the Baltic Sea north of $59^{\circ} \mathrm{N}$ the interannual variabilities of mean ice cover, SST and wind speed show that wind speed during winter (December to February) is negatively correlated to ice cover with correlation factors of $\mathrm{R}=-0.78$ (RCAO-E) and $\mathrm{R}$ $=-0.68(\mathrm{RCAO}-\mathrm{H})$ while the temperature is correlated to the wind speed with correlation factors of $\mathrm{R}=$ 0.72 (RCAO-E) and $\mathrm{R}=0.80$ (RCAO-H). The negative correlation between ice cover and wind speed in this area decreases in the future scenarios with overall decreasing ice cover. During summer (June to August) RCAO-E simulates a slight weakening of the SLP gradient over the southern Baltic Sea, leading to weaker winds. At the same time RCAO-H simulates a slightly stronger SLP gradient (Räisänen et al. 2004, their Fig. 4). The combination of this increase of the SLP gradient and stability changes due to large increases in SST in the RCAO-H runs leads to the relatively strong increases in wind speed. The altered SLP gradient in the RCAO-E runs leads to weaker winds in the southern Baltic Sea and slightly stronger winds in the north.

The results of the 4 regional scenarios are now used to compile future projections of the winter mean $\mathrm{SSH}$ for 2071 to 2100, considering the rise of the global mean sea level calculated from AOGCM scenarios (Section 2.4) and land uplift (Section 2.5). In our 'lower case' scenario the future winter mean $\mathrm{SSH}$ in the Baltic Sea is lower than the annual mean SSH of the control climate, except in regions with subsidence close to the German and Polish coasts (Fig. 7). In this scenario, the overall land uplift is larger than the assumed global average sea level rise of $9 \mathrm{~cm}$. The calculated $\mathrm{SSH}$ increase in the southern Baltic is very small (e.g. only $3 \mathrm{~cm}$ at Gdansk, which is the difference between the scenario and control simulations shown in Fig. 7a,b, respectively). In the 'ensemble average', the future mean $\mathrm{SSH}$ is increasing in the southern Baltic, Baltic proper and Gulf of Finland and decreasing in the Bay of Bothnia and Bothnian Sea. The largest increases are found in the southern Baltic (e.g. $48 \mathrm{~cm}$ at Gdansk) and in the eastern Gulf of Finland (e.g. $42 \mathrm{~cm}$ at St. Petersburg). In our 'higher case' scenario a future mean $\mathrm{SSH}$ increase is found in the entire model domain. Large increases of 97 and $95 \mathrm{~cm}$ are projected for Gdansk and St. Petersburg, respectively. Even at Stockholm the winter mean sea level will be higher in the future (about $43 \mathrm{~cm}$ ) compared to the winter mean sea level of the control climate. The projected winter mean sea level changes for 2071 to 2100 are generally larger than the biases of the control simulations. For example, the winter mean sea level biases in MPICTL (Fig. 7a) amount only to $-2,2$, and $-3 \mathrm{~cm}$ at Klagshamn, Stockholm and Ratan, respectively. Consequently, a correction of the scenarios is not necessary, although the mean seasonal cycles of the control simulations are biased (Fig. 4). Land uplift and the global sea level rise are the dominant contributions to the future changes in mean sea level in the Baltic.

Table 3. Model errors of 6-hourly sea levels from H1 at selected tide gauge locations for 1903 to 1998 and in parentheses 1961 to 1990. ME: mean error $(\mathrm{cm})$; RMSE: root mean square error $(\mathrm{cm})$; R: correlation coefficient; VAR: explained variance; MAXM: model maximum $(\mathrm{cm})$; MAXO: observation maximum $(\mathrm{cm})$; maximum values are relative to mean sea level (MSL). Locations shown in Fig. 8

\begin{tabular}{|c|c|c|c|c|c|c|c|c|c|c|c|c|}
\hline \multirow[b]{2}{*}{ Hamina } & \multicolumn{2}{|c|}{$\mathrm{ME}$} & \multicolumn{2}{|c|}{ RMSE } & \multicolumn{2}{|c|}{$\mathrm{R}$} & \multicolumn{2}{|c|}{ VAR } & \multicolumn{2}{|c|}{ MAXM } & \multicolumn{2}{|c|}{ MAXO } \\
\hline & - & $(5.7)$ & - & (16.4) & - & $(0.85)$ & - & $(0.65)$ & - & $(154)$ & - & (161) \\
\hline Helsinki & - & (9.6) & - & $(16.0)$ & - & $(0.88)$ & - & $(0.58)$ & - & (133) & - & (126) \\
\hline Furuögrund & - & (5.3) & - & $(15.3)$ & - & $(0.86)$ & - & $(0.67)$ & - & (114) & - & (147) \\
\hline Ratan & 1.6 & (3.6) & 14.0 & (13.3) & 0.84 & $(0.88)$ & 0.66 & $(0.72)$ & 137 & (110) & 132 & (132) \\
\hline Stockholm & 1.1 & (3.0) & 12.4 & (11.0) & 0.83 & $(0.88)$ & 0.59 & $(0.70)$ & 121 & $(98)$ & 107 & (107) \\
\hline Landsort & 0.9 & (3.1) & 10.2 & $(9.7)$ & 0.88 & $(0.91)$ & 0.71 & $(0.77)$ & 120 & (95) & 94 & (94) \\
\hline Kungsholmsfort & 6.2 & (7.6) & 13.9 & (14.1) & 0.79 & $(0.82)$ & 0.47 & $(0.49)$ & 110 & $(94)$ & 128 & (106) \\
\hline Klagshamn & - & (2.1) & - & $(14.0)$ & - & $(0.73)$ & - & $(0.46)$ & 81 & (71) & - & (130) \\
\hline
\end{tabular}




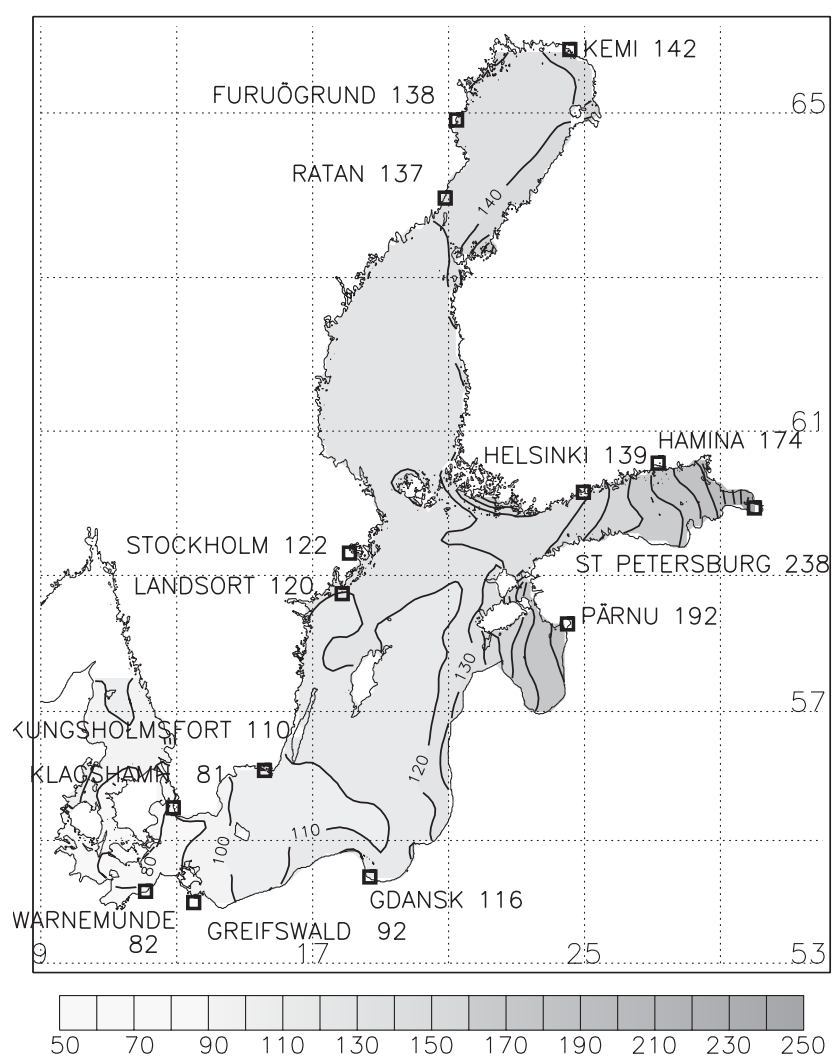

Fig. 8. Maximum relative to the mean sea surface height (SSH, cm) for 1903 to 1998 (hindcast simulation H1). Contour interval: $10 \mathrm{~cm}$

\subsection{Sea level variability and extremes}

The errors for 1903 to 1998 and 1961 to 1990 of the simulated sea level in $\mathrm{H} 1$ at stations with available long records of observations are summarized in Table 3 . The relatively large mean error at Kungsholmsfort is explained by an anomalous MSL value in NH60, very likely caused by a local leveling error (Ekman \& Mäkinen 1996). The large mean biases at Hamina and Helsinki are related to the overestimation of the mean reconstructed surface wind (Section 3.1). The observed sea level variability is simulated well in H1. Even extremes of the past century are reproduced by the model approximately, except in the western Baltic Sea, e.g. at Klagshamn (Fig. 8). Due to the coarse grid resolution of 6 nautical miles, volume transport through the Danish straits is overestimated at time scales $<1$ mo. Consequently, storm surges in the western Baltic caused by NE winds are underestimated. Baerens \& Hupfer (1999) investigated light, medium, and extreme storm surges on the German Baltic coast, classified as events $>100 \mathrm{~cm},>125 \mathrm{~cm}$, and $>150 \mathrm{~cm}$ in the German Kronstadt system (corresponding to $>114 \mathrm{~cm},>139 \mathrm{~cm}$, and $>164 \mathrm{~cm}$ in NH60; Ekman 1999b), finding for example in Warnemünde 84 storm surges during 1901 to 1996. These extreme events are missing in the model simulation. The highest simulated sea level during 1903 to 1998 is only $79 \mathrm{~cm}$ in NH60, or $82 \mathrm{~cm}$ above MSL (Fig. 8). However, the maxima along the Swedish east coast and along the Finnish coasts are simulated satisfactorily (Table 3). For 1903 to 1998 the highest simulated maximum sea level of $238 \mathrm{~cm}$ above mean SSH is found at St. Petersburg; according to Alenius et al. (1998) the highest observed water levels were $321 \mathrm{~cm} \mathrm{(1777),} 421 \mathrm{~cm}$ (1824), $380 \mathrm{~cm}$ (1924), $286 \mathrm{~cm}$ (1955), and $260 \mathrm{~cm}$ (1986). Note, however, that extreme sea levels of both model results and observations may be underestimated, because in this study a time resolution of $6 \mathrm{~h}$ is used. The eastern coasts of the Gulf of Finland and the Gulf of Riga are exposed to non-linear piling up of the water during storm surges (Fig. 8).

In the following we investigate the $30 \mathrm{yr}$ mean intramonthly $99 \%$ quantiles of the sea level. Sea level observations show a pronounced annual cycle as for the monthly mean sea level (Fig. 9a). In the present climate the mean $99 \%$ quantiles are highest during November to January at the ends of the gulfs. In the hindcast simulation (H1) the annual cycle is slightly underestimated in the northern and eastern parts of the Baltic (Fig. 9b). However, these biases are statistically not significant for most months. Larger statistically significant negative and positive biases are found for Klagshamn and Stockholm, respectively. As for the monthly mean sea level (Fig. 4) the errors for the mean $99 \%$ quantiles are much larger in both control simulations compared to the hindcast simulation (e.g. Fig. 9c). In the MPIA2 scenario we found an increase of the mean $99 \%$ quantiles between October and April compared to the control simulation (Fig. 9d). The maximum changes during winter (January to March) are statistically highly significant. The same holds for MPIB2 but with smaller amplitudes (not shown). In HCB2 and HCA2 the changes are statistically not significant. In MPIA2 the increase of the mean $99 \%$ quantiles during winter is even larger than the increase of the monthly mean SSH (Fig. 10). The changes in the eastern part of the Gulf of Finland and Gulf of Riga as well as in the northern part of the Bay of Bothnia are statistically significant at the $99 \%$ confidence limit. Most of these changes located at the ends of the gulfs are associated with internal oscillations of periods $<1$ mo. At Kemi and St. Petersburg even 47 and $74 \%$ of the simulated changes of the $99 \%$ quantiles relative to the winter MSL are associated with oscillations of periods $<2 \mathrm{~d}$. Although simulated $99 \%$ quantiles in the Belt Sea and Arkona Sea are underestimated, we found a local maximum of the changes in this area as well, e.g. at Greif- 
a
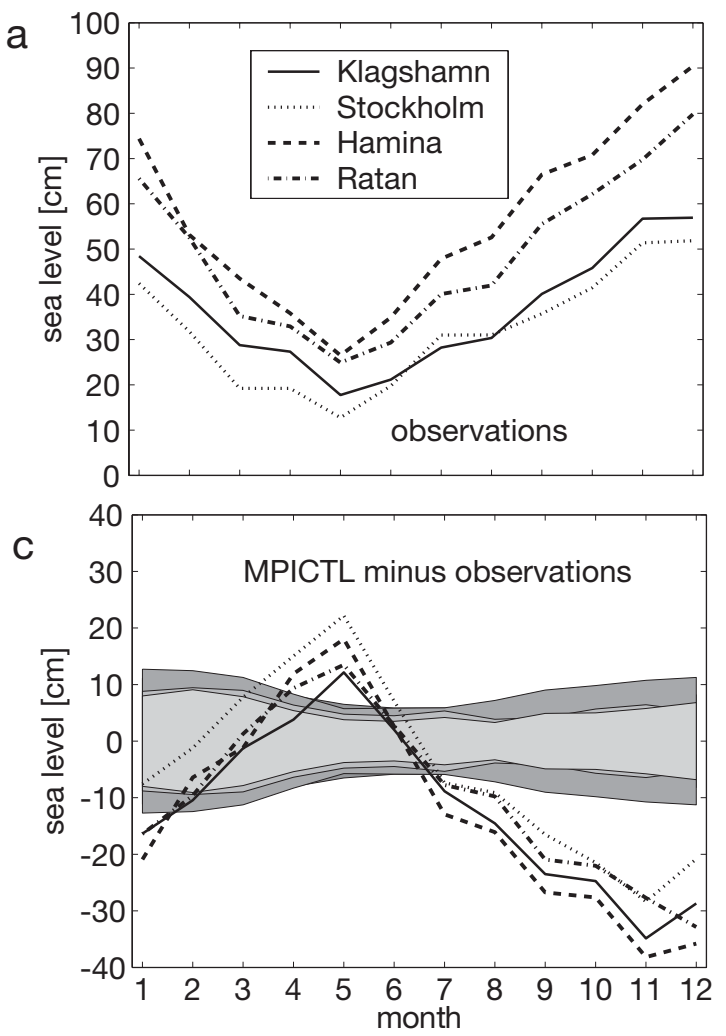

b

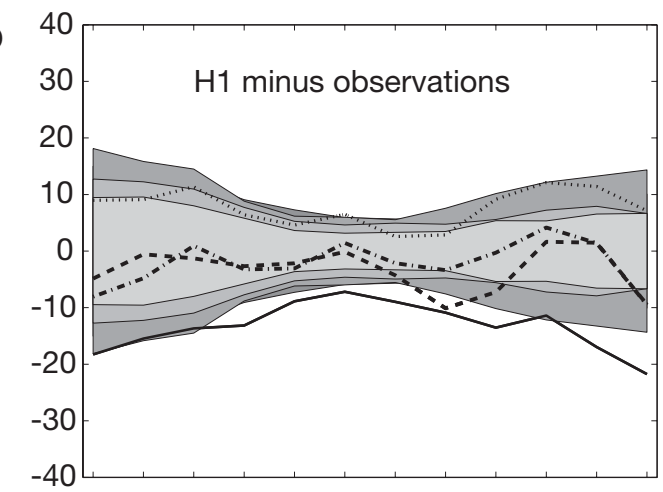

d

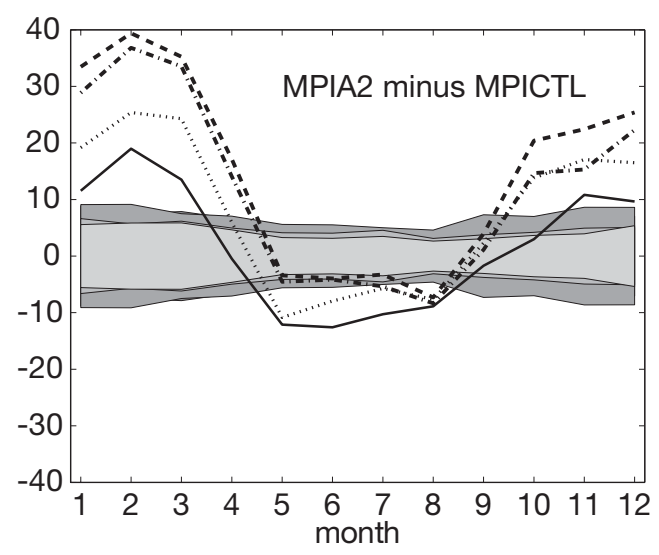

Fig. 9. Climatological mean intra-monthly 99\% quantiles of the sea level (cm) for 1961 to 1990 at selected stations in the Nordic height system 1960 (NH60). Shading indicates the approximate $99 \%$ confidence limits of internal variability (from light grey for Klagshamn to dark grey for Ratan)
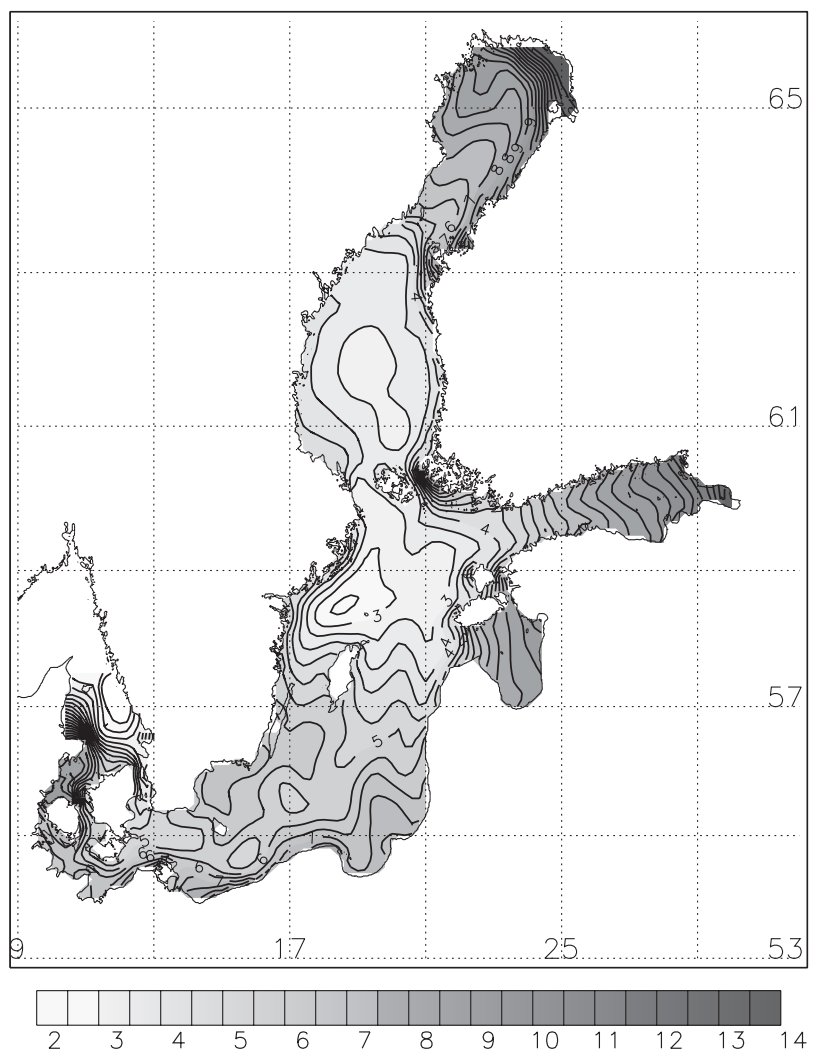

swald (Fig. 10), but they are statistically not significant. The changes are smallest close to the nodal line of the first seiche of the system between the western Baltic and the Gulf of Finland (Neumann 1941).

As the annual cycles of the winter mean $99 \%$ quantiles of the sea level in both control simulations are biased, we applied the $\Delta$-change approach to calculate projections of future extremes for 2071 to 2100 . The changes of the winter mean $99 \%$ quantiles between scenario and control simulations (HC or MPI) were added to the winter mean $99 \%$ quantiles in the hindcast simulation (H1) relative to the MSL during 1961 to 1990. Further, the rise of the global average sea level (Section 2.4) and land uplift (Section 2.5) were considered. In our 'lower case' scenario the future winter mean $99 \%$ quantiles in the Baltic Sea are lower than those during 1961 to 1990 , except in the regions with subsidence close to the German and Polish coasts (Fig. 11). The calculated increase of the $99 \%$ quantiles in the southern Baltic is very small (e.g. only $4 \mathrm{~cm}$ at

Fig. 10. Change of the winter (December to February) mean $99 \%$ quantile minus the change of the winter mean SSH (in $\mathrm{cm}$ ) between MPIA2 and MPICTL. Contour interval: $0.5 \mathrm{~cm}$ 

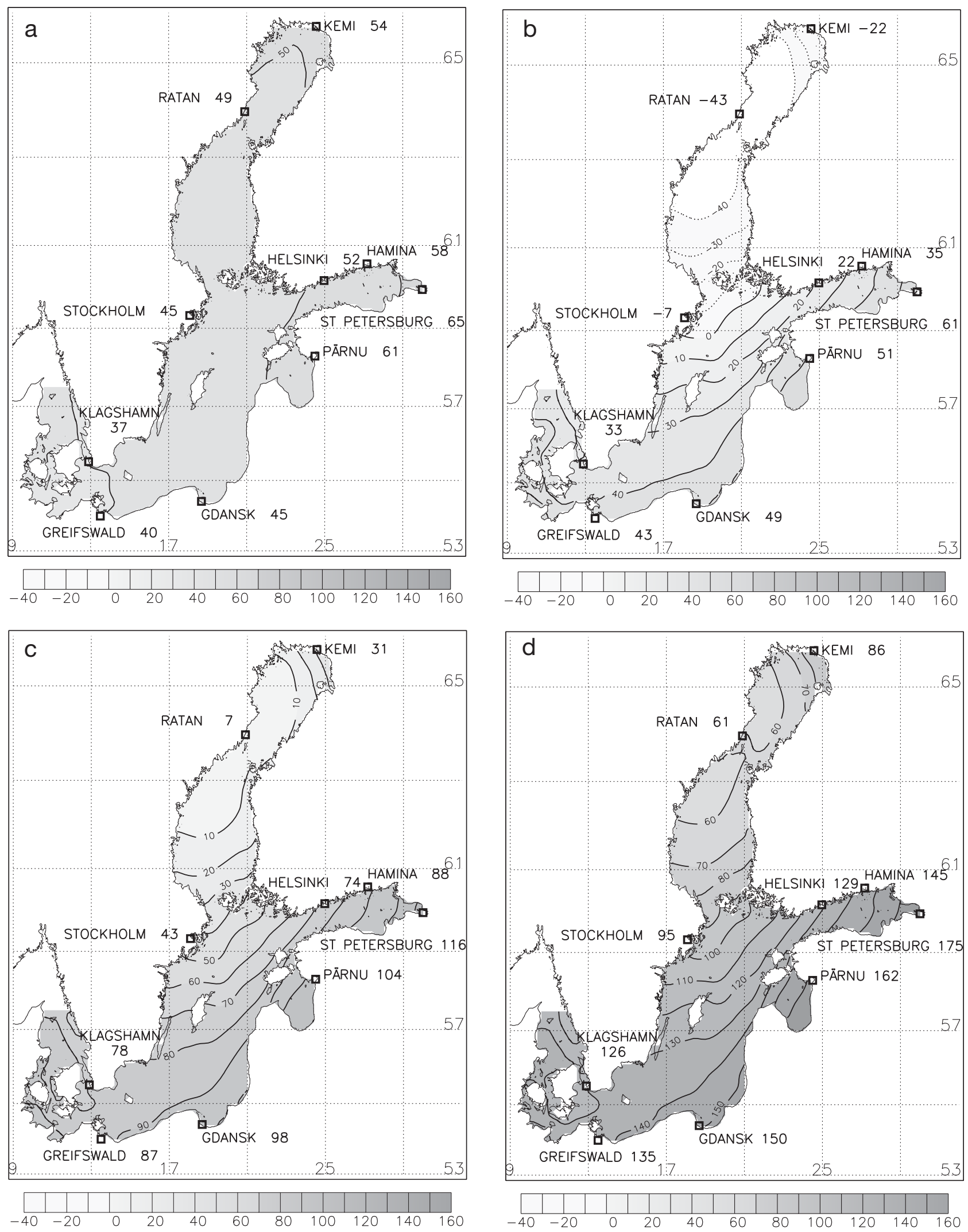

Fig. 11. Climatological winter (December to February) mean $99 \%$ quantiles of the sea level (cm) relative to the mean sea surface height (SSH, cm) for 1961 to 1990. (a) Hindcast simulation (H1) 1961 to 1990. (b) 'Lower case' scenario (HCB2) with a sea level rise of $9 \mathrm{~cm}$. (c) 'Ensemble average' with a sea level rise of $48 \mathrm{~cm}$. (d) 'Higher case' scenario (MPIA2) with a sea level rise of $88 \mathrm{~cm}$. The $\Delta$-change approach is applied and land uplift is considered in the simulations (see text). Contour interval: $10 \mathrm{~cm}$ 
Table 4. Probability (\%) that sea surface height (SSH) will exceed given levels; Max.: maximum $(\mathrm{cm})$ relative to mean sea level 1961 to 1990. Hindcast: H1 simulation for 1903 to 1998; Lower case: HCB2 scenario with sea level rise of $9 \mathrm{~cm}$; 'Ensemble average': sea level rise of $48 \mathrm{~cm}$; Higher case: MPIA2 scenario with sea level rise of $88 \mathrm{~cm}$. Scenarios calculated with the $\Delta$-change approach using $\mathrm{H} 1$ results. Locations shown in Fig. 8

\begin{tabular}{|c|c|c|c|c|}
\hline $\mathrm{SSH}(\mathrm{cm})$ & Hindcast & $\begin{array}{c}\text { Lower } \\
\text { case }\end{array}$ & $\begin{array}{l}\text { 'Ensemble } \\
\text { average' }\end{array}$ & $\begin{array}{l}\text { Higher } \\
\text { case }\end{array}$ \\
\hline \multicolumn{5}{|c|}{ Greifswald } \\
\hline 100 & 0 & 0 & 0.22 & 17.0 \\
\hline 120 & 0 & 0 & 0.02 & 3.25 \\
\hline 140 & 0 & 0 & 0 & 0.38 \\
\hline 160 & 0 & 0 & 0 & 0.05 \\
\hline Max. & 92 & 94 & 137 & 184 \\
\hline \multicolumn{5}{|c|}{ Stockholm } \\
\hline 100 & 0.03 & 0 & 0.02 & 1.32 \\
\hline 120 & 0.005 & 0 & 0 & 0.23 \\
\hline 140 & 0 & 0 & 0 & 0.04 \\
\hline 160 & 0 & 0 & 0 & 0.009 \\
\hline Max. & 124 & 73 & 120 & 171 \\
\hline \multicolumn{5}{|l|}{ Gdansk } \\
\hline 100 & 0.01 & 0.02 & 1.41 & 27.5 \\
\hline 120 & 0 & 0 & 0.21 & 8.90 \\
\hline 140 & 0 & 0 & 0.03 & 2.37 \\
\hline 160 & 0 & 0 & 0.003 & 0.43 \\
\hline Max. & 118 & 123 & 168 & 219 \\
\hline \multicolumn{5}{|l|}{ Pärnu } \\
\hline 100 & 0.46 & 0.24 & 2.91 & 23.2 \\
\hline 120 & 0.16 & 0.08 & 1.05 & 10.8 \\
\hline 140 & 0.05 & 0.03 & 0.37 & 4.73 \\
\hline 160 & 0.02 & 0.006 & 0.12 & 1.90 \\
\hline Max. & 201 & 190 & 241 & 299 \\
\hline \multicolumn{5}{|l|}{ Helsinki } \\
\hline 100 & 0.15 & 0.01 & 0.54 & 9.46 \\
\hline 120 & 0.04 & 0 & 0.12 & 3.61 \\
\hline 140 & 0.003 & 0 & 0.03 & 1.19 \\
\hline 160 & 0 & 0 & 0.001 & 0.30 \\
\hline Max. & 141 & 111 & 161 & 218 \\
\hline \multicolumn{5}{|l|}{ Hamina } \\
\hline 100 & 0.34 & 0.08 & 1.35 & 14.9 \\
\hline 120 & 0.10 & 0.02 & 0.44 & 6.53 \\
\hline 140 & 0.03 & 0 & 0.13 & 2.56 \\
\hline 160 & 0.002 & 0 & 0.03 & 0.90 \\
\hline Max. & 179 & 157 & 202 & 250 \\
\hline \multicolumn{5}{|c|}{ St. Petersburg } \\
\hline 100 & 0.50 & 0.35 & 3.99 & 29.4 \\
\hline 120 & 0.18 & 0.12 & 1.48 & 14.5 \\
\hline 140 & 0.05 & 0.04 & 0.54 & 6.52 \\
\hline 160 & 0.01 & 0.009 & 0.19 & 2.70 \\
\hline Max. & 240 & 235 & 281 & 329 \\
\hline \multicolumn{5}{|l|}{ Kemi } \\
\hline 100 & 0.19 & 0 & 0.006 & 0.63 \\
\hline 120 & 0.04 & 0 & 0 & 0.12 \\
\hline 140 & 0.002 & 0 & 0 & 0.03 \\
\hline 160 & 0 & 0 & 0 & 0.003 \\
\hline Max. & 145 & 61 & 112 & 171 \\
\hline
\end{tabular}

Gdansk). In the 'ensemble average', the future winter mean 99\% quantiles increase in the southern Baltic, Baltic proper and Gulf of Finland and decrease in the Bay of Bothnia and Bothnian Sea. The largest increases are found in the southern Baltic (e.g. $53 \mathrm{~cm}$ at Gdansk) and in the eastern Gulf of Finland (e.g. $51 \mathrm{~cm}$ at St. Petersburg). In our 'higher case' scenario an increase of the future winter mean $99 \%$ quantiles is found in the entire model domain. Large increases of 105 and $110 \mathrm{~cm}$ are projected for Gdansk and St. Petersburg, respectively. Even at Stockholm the winter mean $99 \%$ quantiles will be higher by about $50 \mathrm{~cm}$ in the future, compared to the winter mean $99 \%$ quantiles during 1961 to 1990. These changes are somewhat larger than the changes of the winter mean sea level (cf. Fig. 7) because the $99 \%$ quantiles in the MPI scenarios increase more than the means (Fig. 10). The projected changes of the winter mean $99 \%$ quantiles for 2071 to 2100 are generally larger than the biases of the hindcast simulation for 1961 to 1990, which for example amount to $-17,3$, and $-15 \mathrm{~cm}$ at Klagshamn, Stockholm and Ratan, respectively.

For practical purposes, it would be interesting to estimate extreme events that are more rare than the $30 \mathrm{yr}$ winter mean $99 \%$ quantiles of the sea level. However, due to the limited period, we cannot calculate statistically significant changes for them. Therefore, we assume in the following that the variability of extremes recorded during the 20th century will not change in future. As the simulated changes of the extremes relative to the monthly mean sea level are small compared to the height of observed extremes during 1903 to 1998 (Table 3), i.e. <14 cm (Fig. 10), the omission of this possible contribution is justified. We applied the $\Delta$-change approach using results of the hindcast simulation (H1) for 1903 to 1998 and the changes of the monthly mean sea level between the scenario and control simulations to estimate the probability for the sea level exceeding certain levels (Table 4). To avoid any model biases it would be better to use observations instead of model results. However, there are only a few stations in the Baltic Sea with sufficiently long records of observations and sufficient temporal resolution to analyze storm surges. Except for the Swedish stations, these observations were not available to us. As the highest risk for flooding in the future is expected to occur at the eastern ends of the Gulf of Finland and Gulf of Riga, and in Gdansk Bay (Fig. 11), we utilized the model results of $\mathrm{H1}$, and analyzed the results for 8 representative stations (Table 4). A probability of $0.01 \%$ corresponds, for instance, to 14 events in 96 yr with a duration of 6 $\mathrm{h}$ each. In the present climate, a probability of at least $0.01 \%$ to exceed a sea level of $160 \mathrm{~cm}$ above the MSL is found only for the stations Pärnu and St. Peters- 
burg. At Greifswald, Stockholm, Gdansk, and Helsinki such a risk is calculated only for the 'higher case' scenario, and for Pärnu and Hamina also for the 'ensemble average' scenario. At St. Petersburg the probability of exceeding $160 \mathrm{~cm}$ is $>0.01 \%$ in all 3 scenarios, whereas at Kemi this probability is always lower.

\section{DISCUSSION}

Scenarios are affected by many uncertainties due to the unknown future emission and concentration of greenhouse gases worldwide, by shortcomings of global and regional models, and by internal variability which might mask anthropogenically induced climate trends. In this study, we have characterized the uncertainty in regional sea level scenarios by combining a range of simulated global eustatic sea level rises with the impact of simulated regional wind changes. However, the uncertainty reproduced in this way is limited and does not sample the full range of uncertainty. Global mean sea level rise may not be representative for the regional sea level rise (Section 2.4). In addition, the mean annual cycles of monthly mean sea level and especially of intra-monthly high percentiles are biased in the control simulations (Figs. $4 \& 9$ ). These biases are caused by underestimates of wind speed. We compared wind speeds of the regional atmosphere model with long-term observations at Landsort (see Fig. 8) which may represent sea wind approximately $(\mathrm{H}$. Alexandersson pers. comm.); however, this point measurement may not be representative for the area of the whole model grid box. Part of the error in the wind speeds results from the global model. A test with 'perfect' boundary conditions from the ECMWF re-analysis project ERA-15 (Gibson et al. 1997) shows that the bias in mean wind speed is reduced to roughly $50 \%$ and that the bias in the 99th percentile is reduced with by $20 \%$ compared to the biases of the control runs. However, even if the effect of erroneous boundary conditions is removed, simulated wind speeds over sea are too low during all seasons. The underestimation is most pronounced in windy conditions, and especially during winter. The annual mean errors in mean wind speed and in the 99th percentile are of the order of 15 and $20 \%$, respectively. To overcome the shortcomings of the regional model system the $\Delta$-change approach was applied. However, significant effects of systematic errors can be ruled out only if the systematic errors are small compared to the changes computed (Machenhauer et al. 1998). This condition is fulfilled for changes of the winter mean sea level, but not for changes of the winter mean $99 \%$ quantiles. Consequently, calculated changes of the high intra-monthly percentiles relative to the monthly mean sea level might be too small. Another obstacle is the underestimation of extremes in the western Baltic Sea. This problem will be solved when an increased grid resolution of the ocean model is used.

An interesting detail is the statistically significant change of the high intra-monthly percentiles relative to the mean sea level during winter; this was not observed in earlier studies for the Baltic Sea (Baerens \& Hupfer 1999) and North Sea (e.g. Langenberg et al. 1999, Kauker \& Langenberg 2000). The statistical model from Baerens \& Hupfer (1999) cannot be used to simulate Baltic volume variations. Consequently, Baerens \& Hupfer (1999) found no significant changes in storm surges. We suggest that in the future climate, extremes of the wind speed will increase more than the mean wind speed in areas where the sea ice has disappeared (e.g. in the Bothnian Sea on average; see Meier et al. 2004) Hence, at the extreme ends of the gulfs, sea level extremes will increase significantly more than the mean sea level (Fig. 10). In addition, there might be a non-linear amplification of the sea level response on wind speed changes for periods $<1$ mo. Increased wind speeds during storm events may locally stir anti-clockwise Kelvin waves with maximum amplitudes at the extreme ends of bays or fjords, e.g. in the Gulf of Finland. Further investigations are still necessary to elucidate the processes involved.

In our 'ensemble average' scenario we found maximum changes of about $50 \mathrm{~cm}$ in winter mean sea level and winter mean $99 \%$ quantiles of the sea level at the eastern and southern coasts of the Baltic Sea. Such an increase of the sea level may not be critical, at least not for the large cities, but at some locations the projected extremes of the 'higher case' scenario may be of concern. In the following, the potential risk at 4 study sites is discussed briefly.

For the city of Helsinki a critical value today is 140 to $150 \mathrm{~cm}$ relative to the MSL (S. Lehtonen pers. comm.). During 1900 to 2000 the highest sea level above the theoretical MSL was recorded at $136 \mathrm{~cm}$ on 27 January 1990 (Alenius et al. 1998). According to the guidelines of the Helsinki building code 2000 (see www. rakvv.hel.fi/Rakennusjärjestys/5.luku.htm) the city of Helsinki should be prepared for such worst cases in 2100. Assuming a MSL rise of $100 \mathrm{~cm}$ and a local wave height of $30 \mathrm{~cm}$ the guidelines demand that new buildings be placed so that water levels up to a critical value of $260 \mathrm{~cm}$ relative to the $1990 \mathrm{MSL}$ will not cause damage. We found about the same critical value in our 'higher case' scenario when a eustatic sea level rise of $100 \mathrm{~cm}$ instead of $88 \mathrm{~cm}$ and an additional height for the waves of $30 \mathrm{~cm}$ were considered (Table 4).

At Stockholm, the highest historical water level occurred on 18 January 1983, at $116 \mathrm{~cm}$ above MSL. 
This value was calculated from hourly data and is somewhat higher than in Table 3. As the jetty walls are higher than $180 \mathrm{~cm}$ (H. Bergström pers. comm.), there is no significant risk to the harbor facilities of the Stockholm ports from storm surges in present and future climates according to our scenarios (cf. Table 4). However, some natural or semi-natural shorelines lie lower (areas of Skeppsholmen and Kastellholmen, Djurgården Island, and Hammarby Sjöstad, a big housing estate close to the Baltic; M. Viehhauser pers. comm.).

At Greifswald, the highest historical water level occurred on 12-13 November 1872 at $277 \mathrm{~cm}$ above MSL (Baerens \& Hupfer 1999), although higher water levels were reported for February 1625 (W. Schumacher pers. comm.). Extremes for Greifswald are underestimated in RCO and our scenarios should not be used for impact studies. Taking only land uplift and a sea level rise of $88 \mathrm{~cm}$ into account, a critical value for 2100 would be $363 \mathrm{~cm}$ above the $1990 \mathrm{MSL}$. The State Ministry of Environment of Mecklenburg-Vorpommern assumes a smaller sea level rise, planning with a design flood of $313 \mathrm{~cm}$ above MSL (www.um.mvregierung.de/kuestenschutz/bplan/).

The most serious flooding risk exists at St. Petersburg, which has been flooded more than 280 times since 1703 (Alenius et al. 1998). The highest water level measured was $421 \mathrm{~cm}$ above MSL in 1824. For 2100 the risk for storm surges $>160 \mathrm{~cm}$ is 19 times larger in the 'ensemble average' scenario and 270 times larger in the 'higher case' scenario, compared to the 20th century (Table 4).

The discussion of the 4 sites shows that our study may be relevant for long-term planning especially in the eastern and southern Baltic Sea region. Similar estimates for the Finnish station Hanko were provided by Johansson et al. (2004, their Table 3).

Waves are not included in our study. The impact of waves at higher water levels may be larger than at lower levels, because wave breakers are built for a water height at MSL.

\section{CONCLUSIONS}

(1) The results of the RCO hindcast experiment for 1903 to 1998 are quite close to observations. The mean $\mathrm{SSH}$, mean annual cycle, and storm surges of the past century are reliably simulated, emphasizing the high quality of the reconstructed surface wind and SLP fields. Biases in simulated MSL are mainly associated with uncertainties in the wind fields, rather than with uncertainties in the freshwater inflow. The statistics of storm surges in the Baltic proper and in the gulfs are simulated satisfactorily. However, extremes in the Belt
Sea and Arkona Sea are underestimated, very likely due to the coarse grid resolution of the model.

(2) In the 2 control simulations of RCAO with boundary data from 2 different global models, mean $\mathrm{SSH}$ is simulated well, but the mean annual cycle is biased and sea level extremes are significantly underestimated in the entire model domain. Thus a straightforward application of the scenarios to project future storm surges is impossible. State-of-the-art scenarios are based upon the $\Delta$-change approach.

(3) There is no agreement among our sea level scenarios, due to the large range of projected global average sea level rises. In addition, it is unclear whether regional winds (including the volume balance) will change or not, giving rise to a large degree of uncertainty in the scenarios. In our 'lower case' scenario land uplift in the Baltic region is larger than the sea level rise almost everywhere, and the regional wind does not change significantly. In our 'higher case' scenario, mean and extreme sea levels are higher compared to the reference period in the entire Baltic. Therefore, it is impossible to quantify the risk for coastal areas from sea level rise and storm surge changes in future climate.

(4) Extremes may increase more than monthly mean sea level. In the MPI scenarios, stability decreases in areas where ice is melting, leading to local increases in storminess. Such regional features will be resolved only if a regional climate model for the downscaling of global change is used.

Acknowledgements. This study was carried out partly within the Swedish Regional Climate Modelling programme (SWECLIM, 1997-2003) and partly within the Baltic Sea Region INTERREG IIIB project 'Sea level change affecting the spatial development in the Baltic Sea region' (SEAREG, 2002-2005). Financial support from the Foundation for Strategic Environmental Research (MISTRA), the Swedish Meteorological and Hydrological Institute (SMHI), and the European Regional Development Fund (ERDF) is gratefully acknowledged. The Rossby Centre climate scenarios were the result of a collaborative effort of all staff members. The Finnish Institute for Marine Research (FIMR) in Helsinki provided sea level data of the tide gauges at Hamina and Helsinki for 1960 to 1990.

\section{LITERATURE CITED}

Alenius P, Myrberg K, Nekrasov A (1998) The physical oceanography of the Gulf of Finland: a review. Boreal Environ Res 3:97-125

Alexandersson H, Schmith T, Iden K, Tuomenvirta H (1998) Long-term variations of the storm climate over NW Europe. Global Atmos Ocean Syst 6:97-120

Alexandersson H, Tuomenvirta H, Schmith T, Iden K (2000) Trends of storms in NW Europe derived from an updated pressure data set. Clim Res 14:71-73

Andersson HC (2002) Influence of long-term regional and large-scale atmospheric circulation on the Baltic sea level. Tellus 54A:76-88 
Baerens C, Hupfer P (1999) Extremwasserstände an der deutschen Ostseeküste nach Beobachtungen und in einem Treibhausgasszenario. Küste 61:47-72

Barnston AG, Livezey RE (1987) Classification, seasonality and persistence of low-frequency atmospheric circulation patterns. Mon Weather Rev 115:1083-1126

Church JA, Gregory JM, Huybrechts P, Kuhn M, Lambeck K, Nhuan MT, Qin D, Woodworth PL (2001) Changes in sea level. In: Houghton JT, Ding Y, Griggs DJ, Noguer M, van der Linden PJ, Dai X, Maskell K, Johnson CA (eds) Climate change 2001: The scientific basis. Contribution of working group I to the third assessment report of the intergovernmental panel on climate change. Cambridge University Press, Cambridge, p 640-693

Döscher R, Meier HEM (2004) Simulated sea surface temperature and heat fluxes in different climates of the Baltic Sea. Ambio, 33:242-248

Döscher R, Willén U, Jones C, Rutgersson A, Meier HEM, Hansson U, Graham LP (2002) The development of the regional coupled ocean-atmosphere model RCAO. Boreal Environ Res 7:183-192

Ekman M (1996) A consistent map of the postglacial uplift of Fennoscandia. Terra Nova 8:158-165

Ekman M (1999a) Climate changes detected through the world's longest sea level series. Global Planet Change 21: 215-224

Ekman M (1999b) Using mean sea surface topography for determination of height system differences across the Baltic Sea. Mar Geodesy 22:31-35

Ekman M, Mäkinen J (1996) Mean sea surface topography in the Baltic Sea and its transition area to the North Sea: a geodetic solution and comparison with oceanographic models. J Geophys Res 101:11993-11999

Gibson JK, Kållberg P, Uppala S, Hernandez A, Nomura A, Serrano E (1997) ERA description. ECMWF Re-analysis Project Rep Ser 1, European Centre for Medium-Range Weather Forecasts, Reading, UK

Gordon C, Cooper C, Senior CA, Banks H, Gregory JM, Johns TC, Mitchell JFB, Wood RA (2000) The simulation of SST, sea ice extent and ocean heat transports in a version of the Hadley Centre coupled model without flux adjustments. Clim Dyn 16:147-166

Gornitz V (1995) Monitoring sea level changes. Clim Change 31:515-544

Gustafsson BG, Andersson HC (2001) Modeling the exchange of the Baltic Sea from the meridional atmospheric pressure difference across the North Sea. J Geophys Res 106: 19731-19744

Haapala J, Meier HEM, Rinne J (2001) Numerical investigations of future ice conditions in the Baltic Sea. Ambio 30: $237-244$

Heyen H, Zorita E, von Storch H (1996) Statistical downscaling of monthly mean North Atlantic air-pressure to sea level anomalies in the Baltic Sea. Tellus 48A:312-323

Hurrell JW (1995) Decadal trends in the North Atlantic Oscillation: Regional temperatures and precipitation. Science 269:676-679

Johansson M, Boman H, Kahma KK, Launiainen J (2001) Trends in sea level variability in the Baltic Sea. Boreal Environ Res 6:159-179

Johansson MM, Kahma KK, Boman H (2003) An improved estimate for the long-term mean sea level on the Finnish coast. Geophysica 39:51-73

Johansson MM, Kahma KK, Boman H, Launiainen J (2004) Scenarios for sea level on the Finnish coast. Boreal Environ Res 9:153-166

Jones PD, Jonsson T, Wheeler D (1997) Extension to the North
Atlantic Oscillation using early instrumental pressure observations from Gibraltar and South-West Iceland. Int J Climatol 17:1433-1450

Jones R, Hassell D, Murphy J (1997) Configuring new climate models for Europe with improved climatologies via better representation of physical processes. UKMO 2nd year report for MERCURE, EC contract ENV4-CT97-0485

Kauker F, Langenberg H (2000) Two models for the climate change related development of sea levels in the North Sea. A comparison. Clim Res 15:61-67

Kauker F, Meier HEM (2003) Modeling decadal variability of the Baltic Sea. 1. Reconstructing atmospheric surface data for the period 1902-1998. J Geophys Res 108(C8):3267

Langenberg H, Pfizenmayer A, von Storch H, Sündermann J (1999) Storm-related sea level variations along the North Sea coast: natural variability and anthropogenic change. Contin Shelf Res 19:821-842

Lisitzin E (1964) Contribution to the knowledge of land uplift along the Finnish coast. Fennia 89(4):1-22

Lowe JA, Gregory JM, Flather RA (2001) Changes in the occurrence of storm surges around the United Kingdom under a future climate scenario using a dynamic storm surge model driven by the Hadley Centre climate models. Clim Dyn 18:179-188

Machenhauer B, Windelband M, Botzet M, Hesselbjerg-Christensen J, Deque M, Jones RG, Ruti PM, Visconti G (1998) Validation and analysis of regional present-day climate and climate change simulations over Europe. Rep 275, Max-Planck-Institut für Meteorologie, Hamburg, 140 pp

Magaard L, Krauss W (1966) Spektrum der Wasserstandsschwankungen der Ostsee im Jahre 1958. Kieler Meeresforsch 22:155-162

Meier HEM (1996) A regional model of the western Baltic Sea with open boundary conditions and data assimilation (in German). PhD thesis, University of Kiel, Ber Inst Meereskunde 284

Meier HEM (2001) On the parameterization of mixing in three dimensional Baltic Sea models. J Geophys Res 106: 30997-31016

Meier HEM (2002a) Regional ocean climate simulations with a 3D ice-ocean model for the Baltic Sea. Part 1: Model experiments and results for temperature and salinity. Clim Dyn 19:237-253

Meier HEM (2002b) Regional ocean climate simulations with a 3D ice-ocean model for the Baltic Sea. Part 2: Results for sea ice. Clim Dyn 19:255-266

Meier HEM, Faxén T (2002) Performance analysis of a multiprocessor coupled ice-ocean model for the Baltic Sea. J Atmos Ocean Technol 19:114-124

Meier HEM, Kauker F (2002) Simulating Baltic Sea climate for the period 1902-1998 with the Rossby Centre coupled ice-ocean model. Rep Oceanogr 30, Swedish Meteorological and Hydrological Institute, Norrköping

Meier HEM, Kauker F (2003a) Modeling decadal variability of the Baltic Sea. 2. Role of freshwater inflow and largescale atmospheric circulation for salinity. J Geophys Res 108(C11):3368

Meier HEM, Kauker F (2003b) Sensitivity of the Baltic Sea salinity to the freshwater supply. Clim Res 24:231-242

Meier HEM, Döscher R, Coward AC, Nycander J, Döös K (1999) RCO - Rossby Centre regional Ocean climate model: model description (version 1.0) and first results from the hindcast period 1992/93, Rep Oceanogr 26, Swedish Meteorological and Hydrological Institute, Norrköping

Meier HEM, Döscher R, Faxén T (2003) A multiprocessor coupled ice-ocean model for the Baltic Sea: application to salt inflow. J Geophys Res 108(C8):3273 
Meier HEM, Döscher R, Halkka A (2004) Simulated distributions of Baltic sea ice in warming climate and consequences for the winter habitat of the Baltic ringed seal. Ambio, 33:249-256

Nakićenović N, Alcamo J, Davis G, de Vries B and 24 others (2000) Emission scenarios. Special Report of Working Group III of the Intergovernmental Panel on Climate Change. Cambridge University Press, Cambridge

Neumann G (1941) Eigenschwingungen der Ostsee. Arch Dtsch Seewarte Marineobs 61:1-59

Räisänen J, Hansson U, Ullerstig A, Döscher R and 5 others (2003) GCM driven simulations of recent and future climate with the Rossby Centre coupled atmosphere - Baltic Sea regional climate model RCAO. Rep Meteorol Climatol 101, Swedish Meteorological and Hydrological Institute, Norrköping

Räisänen J, Hansson U, Ullerstig A, Döscher R and 5 others (2004) European climate in the late twenty-first century: regional simulations with two driving global models and two forcing scenarios. Clim Dyn 22:13-31

Roeckner E, Bengtsson L, Feichter J, Lelieveld J, Rodhe H

Editorial responsibility: Otto Kinne,

Oldendorf/Luhe, Germany
(1999) Transient climate change simulations with a coupled atmosphere-ocean GCM including the tropospheric sulfur cycle. J Clim 12:3004-3032

Samuelsson M, Stigebrandt A (1996) Main characteristics of the long-term sea level variability in the Baltic Sea. Tellus 48A:672-683

Schrum C, Backhaus JO (1999) Sensitivity of atmosphereocean heat exchange and heat content in the North Sea and the Baltic Sea. Tellus 51A:526-549

Stevens DP (1990) On open boundary conditions for 3 dimensional primitive equation ocean circulation models. Geophys Astrophys Fluid Dyn 51:103-133

Ulbrich U, Christoph M (1999) A shift of the NAO and increasing storm track activity over Europe due to anthropogenic greenhouse gas forcing. Clim Dyn 15:551-559

Vermeer M, Kakkuri J, Mälkki P, Boman H, Kahma KK, Leppäranta M (1988) Land uplift and sea level variability spectrum using fully measured monthly means of tide gauge readings. Finn Mar Res 256:3-75

Wübber C, Krauss W (1979) The two-dimensional seiches of the Baltic Sea. Oceanol Acta 2:435-446

Submitted: January 9, 2004; Accepted: June 1, 2004 Proofs received from author(s): July 12, 2004 